there will be no price war-simply a general famine in which most consultants will see fewer private referrals. Faced with this, they can maintain their income by a mixture of raising their prices and generating extra work by such measures as booking extra follow up appointments. The insurance companies will then experience further rises in the frequency and size of claims. How will they respond?

Insurers already challenge hospitals and doctors who charge high prices, ${ }^{4}$ and many have reduced the conditions for which subscribers are covered. But neither measure is easy to implement effectively, and both carry political risks. Insurers are therefore exploring other options. ${ }^{5}$ In an oversupplied market selected hospitals and doctors may be persuaded to contain prices and practise efficiently in return for a guaranteed volume of referrals. The insurers can then steer their subscribers to these "preferred providers" by using various methods, including financial incentives. These may well be linked to other attempts to control the size of specialists' fees by encouraging developments such as package priced surgery. ${ }^{6}$ Alternatively, rather than risk constraining their subscribers' choice many insurers may prefer to review the appropriateness of more episodes of care than the few very expensive cases that they already look at. Experience from the
United States over the past 10 years suggests that two changes can be expected to such review. Firstly, it will become prospective, with insurers requiring certification or second opinions before admission, and, secondly, it will become participatory, with insurers' agents interacting with providers to ensure that care is focused and efficient as it occurs.

Many of these changes will occur regardless of the outcome of the insurers' present economic woes. The recent appointment to the top job in one of the biggest insurers of someone who previously ran a large sugar company serves to underline that the private health market has come of commercial age. How sweetly the profession takes to the prospect remains to be seen.

\section{JONATHAN BOYCE}

Hanwell,

Oxfordshire OX17 1HN

1 Fieldman S. BUPA posts $£ 63 \mathrm{~m}$ loss: soaring hospital costs hit Britain’s largest private health insurer. Independent on Sunday 1991 Jun 23:15 (business section).

Pike A. BUPA loss as bigger claims take their toll. Financial Times 1991 Jun 27:29.

3 Laing's review of private health care. London: Laing and Buisson, 1991

Christie B. Insurance blacklist threat to private hospital. Scotsman 1991 Jan 11:3.

5 BBC. The Monev Programme. 1992 Jan 12.

6 King's Fund . Going private. London: King's Fund, 1992. (London initiative working paper No 4.)

7 Stricker $\mathrm{G}$, Rodriguez AR, eds. Handbook of quality assurance in mental health. New York: Plenum Press, 1988.

\title{
Motor neurone disease
}

\section{Treating the untreated}

Progressive loss of the $\alpha$ motor neurones in adult life (motor neurone disease) was well described nearly 150 years ago, ${ }^{1}$ yet the cause and a specific treatment or preventive measure continue to elude us. Many doctors and especially neurologists (90\% in our experience) continue to offer no care to patients suffering from this fatal paralysis, as though the lack of a cure is somehow equated with the absence of any treatment. This is curious because patients with many other fatal diseases receive supportive care or palliation from their doctors (including neurologists). Yet a paralysed patient with motor neurone disease is often neglected despite the availability of many symptomatic treatments. ${ }^{23}$

Painful muscle cramps often make life even more miserable for patients, as does the constant drooling some experience, and such manifestations can nearly always be reduced to a tolerable level, if not eliminated altogether. ${ }^{23}$ Severe fatiguability,${ }^{2+5}$ sleep problems, ${ }^{2}$ incipient contractures, subluxation of the shoulder joint, dysphagia ${ }^{2}$ and neuralgia ${ }^{6}$ can all be ameliorated. Drugs may control the extreme emotional lability that is often an early feature of amyotrophic lateral sclerosis. ${ }^{237}$ This results in uncontrollable swings of emotion, usually towards prolonged weeping, which demoralises not only the patient but all those around. These measures can be applied whenever needed in the course of the illness.

A paper in this week's journal by Dr Tony O'Brien, Sister Moira Kelly, and Dame Cicely Saunders describes their experience with patients in the terminal stages of motor neurone disease, immediately before and during respiratory failure (p 471). ${ }^{8}$ Perhaps their most important point is confirmation that giving generous doses of narcotic drugs at this time is safe, non-addictive, and effective. ${ }^{9}$ Transient improvement may even occur in some patients, over and above the expected analgesic and euphoric effects; both morphine and pethidine seem equally effective.
As most patients terminally ill with motor neurone disease suffer from dysphagia, narcotic drugs should be given subcutaneously (in the same way as insulin is given) unless intravenous access exists. The subcutaneous route seems effective and is readily taught to patients' families for use at home.

The management of motor neurone disease in the United States differs in several respects from that in Britain. American patients are more likely to be offered respiratory support; with help from family and friends some of these patients can be very successfully managed at home, ${ }^{1011}$ thereby avoiding prolonged stays in hospital. Also, in the United States considerably more than the $8 \%$ of terminally ill patients reported by O'Brien and colleagues ${ }^{8}$ undergo catheter gastrostomy. Gastrostomy, which has been revolutionised by the catheter procedure,,$^{12}$ spares patients the pain of aspirating food and drink as well as the distress of dehydration and starvation.

Another major difference in our experiences is that the American hospice movement lags behind that initiated so successfully in Britain by Dame Cicely and her colleagues. ${ }^{813}$ Perhaps on this account, we have encouraged our patients with terminal disease to remain at home if possible, though house calls then become a heavy burden for medical staff. A gradually increasing number of our patients are being admitted to hospices for terminal care, and hospice nurses are actively collaborating in our home care programme.

It was not so many years ago that good doctors regarded the care of the dying and the support of their families as an essential part of their practice-a role not easily delegated to others. Today in the United States bureaucrats and accountants have in effect decreed otherwise. Fortunately research is being done into motor neurone disease, from which we may dare hope for a successful primary treatment and eventual 
disappearance of the need for this symptomatic and supportive approach.

Director,

FORBES H NORRIS

ALS Research Foundation,

San Francisco, California 94115,

USA

1 Aran F-A. Récherches sur une maladie non encore décrite du système musculaire (atrophie musculaire progressive). Archives Générales Médecine 1850;24:15-35, 172-214.

Norris FH, Smith RA, Denys EH. Motor neurone disease: towards better care. BMJ 1985;291:259-62.

3 Norris FH, Smith RA, Denys EH. The treatment of amyotrophic lateral sclerosis. Adv Exp Med Biol 1987;209:175-82.

4 Mulder DW, Lambert EH, Eaton LM. Myasthenic syndrome in patients with amyotrophic lateral sclerosis. Neurology 1959;9:627-31.
5 Denys EH, Norris FH. Amyotrophic lateral sclerosis: impairment of neuromuscular transmission. Arch Neurol 1979;36:202-5.

6 Norris FH. Amyotrophic lateral sclerosis: the clinical picture. In: Smith RA, ed. Handbook of amyotrophic lateral sclerosis. New York: Marcel Dekker, 1992:3-38.

7 Udaka F, Yamao S, Nagata H, Nakamura S, Kameyama N. Pathologic laughing and crying treated with levodopa. Arch Neurol 1984;41:1095-96.

8 O'Brien T, Kelly M, Saunders C. Motor neurone disease: a hospice perspective. BMJ 1992;304:471-3.

9 Norris FH. Adult spinal motor neurone disease. In: Vinken PJ, Bruyn GW, eds. Handbook of clinical neurology. Vol 22, Pt 2. Amsterdam: North Holland Publishing Co, 1975:1-56.

10 Norris FH, Smith RA, Denys EH, Holden D, Elkin R, Fallat RJ, et al. Home care of the paralyzed respirator patient with amyotrophic lateral sclerosis. In: Charash LI, Lovelace RE, Wolf SG, Kutscher AH, Roye DP, Leach CF, eds. Realities in coping with progressive neuromuscular disease. Philadelphia: Charles Press, 1987:72-83.

11 Norris FH, Holden D, Kandal K, Stanley E. Home nursing care by families for severely paralyzed ALS patients. Adv Exp Med Biol 1987;209:231-8.

12 Russell TR, Brotman M, Norris FH. Percutaneous gastrostomy: a new simplified and cost effective technique. Am f Surg 1984;148:132-7.

13 Saunders C, Summers DH, Teller N, eds. Hospice: the living idea. London: Edward Arnold, 1981

\section{Routine weighing during antenatal visits}

\section{Still justified}

Regular measurement of weight gain during pregnancy has traditionally been used to assess the nutritional status of pregnant women. Determining the true nutrient intake from a dietary history is time consuming and may be misleading; sufficient weight gain is the only objective and reliable indicator of an adequate energy intake during pregnancy.

Dawes and Grudzinskas and others have recently suggested that routine weighing of patients should be re-evaluated because it may not be useful in detecting poor fetal growth or pre-eclampsia ${ }^{1}$ and may generate undue anxiety in the patient and staff. ${ }^{2}$ Despite their reservations, however, an association undoubtedly exists between infant birth weight and maternal weight gain in pregnancy, particularly in women who are of normal or less than normal weight at conception. ${ }^{3+}$ Poor weight gain (assessed as either total gain or rate of gain) is significantly associated with poor pregnancy outcome including preterm delivery and intrauterine growth retardation. ${ }^{+7}$ An average weekly gain (especially after 20 weeks' gestation) of less than $0.24 \mathrm{~kg}$ is associated with a higher incidence of both preterm delivery and growth retardation. ${ }^{6}$ If women who have a low booking weight or are gaining weight slowly receive extensive nutritional advice they gain more weight and have infants with a significantly higher birth weight than similar women who do not receive such advice. ${ }^{8}$ Another study showed that counselling women with poor weight gain not only reduced the incidence of low birth weight but was also cost effective. ${ }^{9}$

Women who are of normal weight when they become pregnant and gain weight excessively are at risk of problems at delivery such as caesarean section and assisted deliveries. ${ }^{10}$ Wen et al found that a weekly weight gain of more than 0.75 $\mathrm{kg}$ was associated with preterm labour and speculated that this was due to pre-eclampsia. ${ }^{6}$ Dawes's own data showed that blood pressure was significantly higher in those with the greatest gain in weight during pregnancy. ${ }^{2}$ Excessive incremental weight gain is not diagnostic of pre-eclampsia but could alert practitioners to monitor a woman for other signs and symptoms of pre-eclampsia. Serial assessment of both weight gain and fundal height have been clinically useful in identifying those patients who require ultrasonographic evaluation of fetal growth. "This is more cost effective than doing serial ultrasonographic examinations on all patients.

An adequate weight gain is reassuring for women and those providing their health care, most of whom consider routine weighing to be quite important - as the paper by Dawes and colleagues in this week's journal shows ( $p$ 487). ${ }^{12}$ If not weighed as part of routine antenatal care many women would be likely to weigh themselves at home and then report their concerns to those providing their health care. To be clinically useful weight should be measured on the same scale at the same time of day. Whether information on weight causes anxiety depends on how those providing health care counsel the patient. A large study has shown that medical advice about weight gain had a substantial effect on the actual weight gained by a pregnant woman. In addition, women who received no advice about desired weight gain were more likely to have gained inadequate weight. ${ }^{13}$

Both low and high weight gains may be significant predictors of adverse outcomes. Adequate weight gains should therefore be actively promoted: women of normal weight at the beginning of pregnancy should gain $11 \cdot 5-16 \mathrm{~kg}$, underweight women $13-18 \mathrm{~kg}$, and overweight women $7-11.5 \mathrm{~kg} .^{1+}$ Excessive weight gain may be undesirable and should be discouraged. Periodic weighing allows patients to be counselled before weight gain becomes extreme. Regular weighing will not result in a diagnosis but is valuable as a screening tool. Until we have studies showing that routine weighing is of no value in screening pregnant women for obstetric problems we should not abandon the practice.

DIANE L DIMPERIO Associate in Obstetrics and Gynecology BARBARA H FRENTZEN Associate in Obstetrics and Gynecology AMELIA C CRUZ

Professor of Obstetrics and Gynecology and Pediatrics University of Florida College of Medicine,

Gainesville, Florida 32610, USA

1 Dawes MG, Grudzinskas JG. Patterns of maternal weight gain in pregnancy. $\mathrm{Br} \mathcal{f}$ Obstet Gynaecol 1991;98:195-201.

2 Dawes MG, Grudzinskas JG. Repeated measurement of maternal weight during pregnancy. Is this a useful practice? Br f Obstet Gynaecol 1991;98:189-94.

3 Abrams BF, Laros RK. Prepregnancy weight, weight gain, and birth weight. Am $\mathcal{J}$ Obstet Gynecol 1986;154:503-9.

4 Seidman DS, Ever-Hadani P, Gale R. The effect of maternal weight gain in pregnancy on birth weight. Obstet Gynecol 1989;74:140-6.

5 Abrams B, Newman V, Key T, Parker J. Maternal weight gain and preterm delivery. Obstet Gynecol 1989;74:577-83.

6 Wen SW, Goldenberg RL, Cutter GR, Hoffman HJ, Cliver SP. Intrauterine growth retardation and preterm delivery: prenatal risk factors in an indigent population. Am $\mathcal{J}$ Obstet Gynecol 1990;162:213-8.

7 Abrams B, Parker JD. Maternal weight gain in women with good pregnancy outcome. Obstet Gynecol 1990;76:1-7.

8 Bruce L, Tchabo J-G. Nutrition intervention program in a prenatal clinic. Obstet Gynecol $1989: 74: 310-2$.

9 Orstead C, Arrington D, Kamath SK, Olson R, Kohrs MB. Efficacy of prenatal nutrition counselling: weight gain, infant birth weight, and cost-effectiveness. $\mathcal{f}$ Am Diet Assoc 1985;85:40-5.

10 Shepard MJ, Hellenbrand KG, Bracken MB. Proportional weight gain and complications of pregnancy, labor, and delivery in healthy women of normal stature. Am $\mathcal{J}$ Obstet Gynecol 1986;155:947-54

11 Rosendahl H, Kivinen S. Detection of small for gestational age fetuses by the combination of clinical risk factors and ultrasonography. Eur $\mathcal{F}$ Obstet Gynecol Reprod Biol 1991;39:7-11.

12 Dawes MG, Green J, Ashurst H. Routine weighing in pregnancy. BMf 1992;304:487-9.

13 Taffel SM, Keppel KG. Advice about weight gain during pregnancy and actual weight gain. Am I Public Health 1986;76: 1396-9.

14 Institute of Medicine. Nutrition during pregnancy. Washington: National Academy, 1990 